\title{
Marine Resources and Prehistoric Adaptations: A Review of Trekking the Shore
}

Barry Wood

University of Houston

Correspondence | Barry Wood, barrywood1940@yahoo.com

Citation | Wood, B. (2019) Marine Resources and Prehistoric Adaptations: A Review of Trekking the Shore. Journal of Big History, III(4); 167 - 170.

DOI | https://doi.org/10.22339/jbh.v3i4.3466

n the premier number of Journal of Island \& CoastalArchaeology, Erlandson and Fitzpatrick (2006) note that coastal, maritime, and island environments were long considered "relatively peripheral" for the study of human prehistory. Lifeways study was biased toward "hunting of large land mammals" as primary and "agriculture ... at the root of all human civilization." But recent studies have shown such coastal and marine environments are "increasingly relevant to a variety of important anthropological and historical topics," including the "antiquity of coastal adaptations and maritime migrations" and "the development of specialized maritime technologies and capabilities." Deacon and Deacon (1999), for instance have pointed to extensive use of maritime food resources in South Africa during the early emergence of Homo sapiens (c. 200,000 BCE), while several studies have explored maritime navigation (Clark 1991, Irwin 1992, Howe 2003) that made possible migrations from Island Southeast Asia to the most remote areas of Oceania.

Given increased attention to marine resources and evidence of prehistoric migration along continental margins, the time was right for Trekking the Shore: Changing Coastlines and the Antiquity of Coastal Settlement (2011), a collection of twenty studies by forty anthropologists, archaeologists, biologists, botanists, geographers, and field specialists.

Ground was prepared for the volume by two conference symposia $(2006,2008)$. Their emphases include coastal resources in human evolution, the

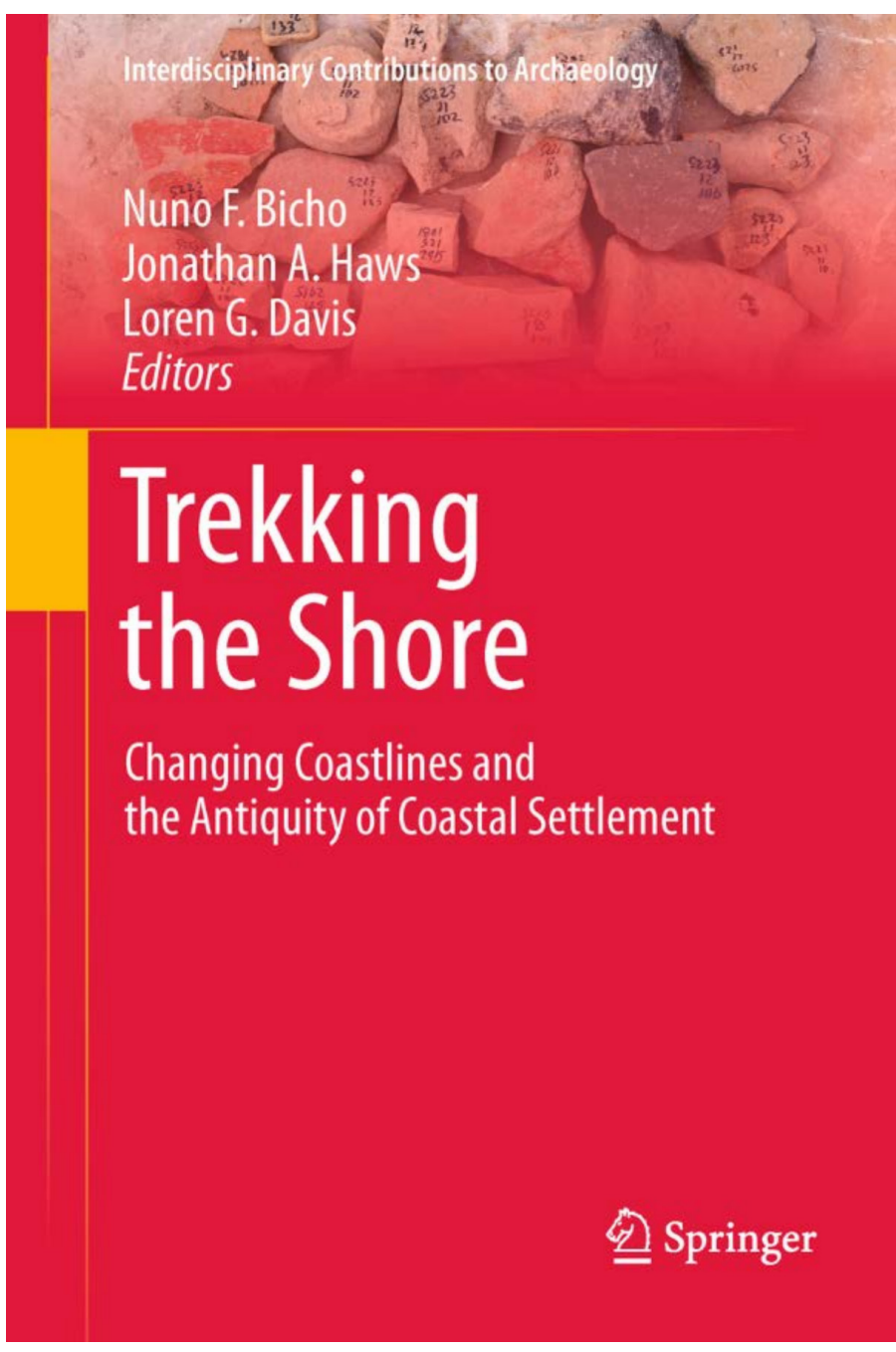

Trekking the Shore (2011), edited by Nuno Bicho et al, provides exhaustive surveys of selected coastal regions, detailing the role of marine resources in human evolution, prehistoric migration, and creative human adaptation stemming from the reliability and richness of marine, estuarial, lacustrine, and riverine environments.

Image source 
role of coastal environments in prehistoric human settlement, and the interplay of human presence along continental margins with sea level changes during eras of glaciation and sea-level change. The result is a thorough scholarly survey of the field to date, each study featuring an exhaustive list of references.

A striking example of the importance of marine food resources has emerged in connection with the long presence (200,000 to $100,000 \mathrm{BP}$ ) of early Homo sapiens in South Africa. The human body does not produce polyunsaturated fatty acids - docosahex acid (DHA) and arachninoid acid (AA); these are produced by aquatic animals and plants. Various studies have linked these to human brain and retinal development during this extended period of continuous reliance on marine food sources. A second recognition centers on the now accepted coastal route of migration out of Africa following coastlines of South Asia (The Southern Dispersal) and recent discoveries pointing to a west coast route for humans entering the New World from Asia (The Coastal Route). These now preferred migration routes have focused anthropological attention on ocean coasts worldwide.

Trekking the Shore is organized in two parts: I. North America and Eurasia, and II. South America, Africa, and Oceania. This organization, as noted by the editors, is "based on latitude," though they are seemingly unaware that this treatment is synchronic rather than diachronic: latitude does not reveal a logic inherent in the subject and, in fact, veers away from the "trekking" of the title which suggests a movement, a continuity, an order, a chronology that is distinctly missing in the volume.

Seven studies (Nos 1 to 7) summarize the evidence for a Pacific coast route for humans entering the Americas. This route has emerged not only from fossil and genetic evidence of human coastal settlement at numerous sites from southeastern Alaska to Patagonia, but also from recognition that the previously preferred route of entry into North America through an interior "ice-free corridor" is no longer viable either ecologically or chronologically. The focus on
Eurasia in five studies (Nos. 8 to 12) has, among other recognitions, extended the reliance on marine resources to earlier migrants out of Africa. Neanderthals, now recognized as probable descendants of Home erectus, who migrated out of Africa up to two million years ago, learned to exploit marine resources in Eurasia while Homo sapiens were developing similar skills in South Africa.

Three studies (Nos. 13-15) assemble evidence from Ecuador, Argentina, and Chile for varying kinds of reliance on marine resources, focusing attention on both the west coast entry of humans into the Americas and their subsequent adaptation to inland riverine environments. Three studies focusing on Africa, one from Morocco (No. 16) and two from South Africa, (Nos. 17-18) suggest a much more extensive use of coastal resources along ten thousand miles of African coastlines, studies of which are not included. The final two studies (Nos. 19 and 20) focus on extensive evidence for coastal settlement along the eastern coast of Australia - a region of substantial population density and thus most thoroughly excavated.

Investigation of coastal sites occupied by Homo sapiens provides much though not necessarily complete evidence for human adaptation to marine migration and settlement. A notable contrast is evident when comparing adaptation at diverse times and places. In a survey of west coast sites of North and South America, Willis and Des Lauriers (2011) summarize technological findings from On Your Knees Cave in Alaska to Indian Sands (Oregon), Daisy Cave (California), Ring Site (Peru) to Monte Verde III (Chile). These date after 11,000 BP, though Monte Verde shows occupation three thousand years earlier. In every case tool assemblages have turned up that include lithic remnants related to seafood harvesting, generally fashioned from local rocks. While occasional tools associated with inland faunal hunting show up, the primary adaptation along the Pacific coast is oriented toward exploitation of marine resources. 
Adistinct contrast is evident from South African sites where extensive excavations have been undertaken at Blombos Cave, Pinnacle Point, and more than a score of early habitation sites. Evidence dates much earlier, to the time of Homo sapiens emergence as a cognitively competent hominid, 200 to 100 thousand years BP (Marean 2011). Evidence of material culture includes beads, decoration with ochre, and pigment experimentation, with very limited seafood hunting tools. Adaptation to the coastal environment is almost exclusively found in middens that indicate extensive and continuous shellfish exploitation that requires gathering rather than hunting. At this early stage of Homo sapiens' development, humans appear to have been foragers rather than active fishers armed with hunting weapons. At much later dates and sites distant from Africa, evidence of coastal adaptation includes not only shellfish middens but also marine exploitation tool assemblies, not only down the west coast of the Americas, but also coastal sites for instance in Portugal (Haws et al, 2011) and the Russian Far East adjacent to the Sea of Okhotsk and Sea of Japan (Tabarev 2011).

Notably missing from Trekking the Shore are surveys of coastal life and adaptation in South and East Asia, the vast region of Island Southeast Asia, and Oceania - the latter two perhaps more dependent on marine food resources than regions covered in the book. The book, however, runs to a substantial 496 pages; additional coverage would have required a second volume. Taken together, these studies provide detailed and thorough analysis of coastal life at many locations around the planet, but the editorial organization into discrete regions - classified by latitude-with little connective commentary mirrors the knowledge departmentalization endemic to academia - in this case a kind of siloized geoanthropology. Big historians are regularly confronted with such silos from which they must extract details and patterns, then organize them according to chronology. This is the contribution of big history to knowledge: the molding of knowledge fragments into a continuous narrative.
With these limitations noted, the volume is important for the sheer scope of material assembled. Following up on the references for each chapter-often more than a hundred - is a formidable task, but the reward is that many references provide the connective narrative; one simply has to search it out. However, one would have hoped the editors had provided a synthesizing introduction that would move the separate essays into a more comprehensive history of human migration which, as noted, is implied in the "trekking" of the title.

From this perspective, it is worth noting that a continuous narrative of prehistoric human migration has yet to be written. One reason is clear: attempting to bring order to migration through the interior spaces of the continents, especially the vast reaches of inland Africa and Eurasia, seems out of reach. But coastal migration is another story. Continental margins may be riddled with bays and estuaries, temporary glacial blockage and torrential rivers, formidable cliffs and crashing surf, but they are continuous, passable by detour, and on calmer coasts, amenable to casual beachcombing. Of the many ways that prehistoric humans peopled the planet, Trekking the Shore points to the only continuous and certain route whereby Homo sapiens migrated from the most remote region of Africa, the southern cape, to equally remote lands end half a world away, the wind-blown mountainous terrain of Patagonia. That story is told elsewhere in this issue.

\section{References}

Bicho, Nuno F., Jonathan A. Haws, Loren G. Davis, eds. 2011. Trekking the Shore: Changing Coastlines and the Antiquity of Coastal Settlement. London: Springer.

Clark, J. T. 1991. "Early Settlement of the Indo-Pacific," Journal of Anthropological Archaeology, Vol. 10, 27-53.

Deacon, H. J. and J. Deacon. 1999. Human Beginnings in South Africa: Uncovering the Secrets of the Stone Age. Walnut Creek, CA; Altamira Press. 
Erlandson, Jon M. and Scott M. Fitzpatrick. 2006. "Oceans, Islands, and Coasts: Current Perspectives on the Role of the Sea in Human Prehistory," Journal of Island \& Coastal Achaeology, Vol I: 5-32.

Haws, Johathan A. 2011. "Paleolithic Landscapes and Seascapes of the West Coast of Portugal.” In Bicho, et al., 203-246.

Howe, K. R. 2003. The Quest for Origins: Who First Discovered and Settled the Pacific Islands? Honolulu: University of Hawai'i Press.

Irwin, G. 1992. The Prehistoric Exploration and Colonisation of the Pacific. Cambridge: Cambridge University Press.

Marean, Curtis. 2011. "Coastal South Africa and the Coevolution of the Modern Human Lineage and the Coastal Adaptation." In Bicho et al., 421-440.

Tabarev, Andrei V. 2011. "Blessing the Salmon: Archaeological Evidences of the Transition to Intensive Fishing in the Final Paleolithic, Maritime Region, Russian Far East." In Bicho et al, 105-116.

Willis, Samuel C. and Matthew R. Des Lauriers. "Early Technological Organization Along the Eastern Pacific Rim of the New World: A Co-Continental View." In Bicho, et al., 117-136. 